\title{
Case report - pulmonary embolism and necessity of echocardiography use in Emergency Department
}

\author{
Andrea Džumhur*, Lana Maričić, Krešimir Jelić, Sandra Makarović \\ University Hospital Center Osijek, Osijek, Croatia
}

\begin{abstract}
A 72-year old man with sudden chest pain, which had started two hours ago, moderate in intensity and character of the oppression, came to Emergency Department (ED). He was hypotensive $(95 / 60 \mathrm{mmHg})$, with cyanotic lips, but not breathless, and was having a heavy vertigo. By physical examination, there were normal breathing sounds, normal heart rhythm, mild tachycardia (92/min), and there was a murmur over the Erb's point. Arterial haemoglobin oxygen saturation was $90.6 \%$. Abdominal and extremities' physical findings were normal. Routine laboratory examination revealed elevated D-dimers (6993ug/L), troponin I (0.274 ug/L), slightly reduced red blood cells count $(4.11 \times 1012 / \mathrm{L})$, haematocrit (0.4), haemoglobin (139 g/L), platelets (149x106/L) and potassium $(3.7 \mathrm{mmol} / \mathrm{L})$. Other laboratory parameters were within normal range. Electrocardiogram showed sinus rhythm, 92/min., and $Q$ in the III lead.

The man was diagnosed with hemodynamic shock, but the cause of the shock was unclear. Differential diagnosis assumed a cardiogenic, a haemorrhagic or a neurologic pathogenesis. Heart ultrasound was performed for evaluation of potential sources of cardiogenic emboli. The echocardiography showed dilated right ventricles $(50 \mathrm{~mm})$, severe tricuspid insufficiency (Vmax. $3.21 \mathrm{~m} / \mathrm{s}, \mathrm{PGmax} .41 .3 \mathrm{mmHg}$ ), with estimated severe pulmonary hypertension $(60 \mathrm{mmHg})$. Also, there were compressed left ventricles $(39 \mathrm{~mm})$, with preserved systolic function, and "kissing phenomena".
\end{abstract}

Thus pulmonary embolism (PE) was strongly suspected and CT angiography of pulmonary arteries showed massive PE. A half an hour following alteplase and unfractionated heparin administration, arterial pressure started to normalize, and repeated heart echocardiography showed normalization of the ventricular dimensions, with reduction of the pulmonary hypertension. The patient began feeling well, while the vertigo and the chest pain disappeared. During the next few days his condition completely restituted.

By that particular case of not typically presented massive pulmonary embolism, the heart echo facilitated the diagnostic procedure, and justified the necessity of heart ultrasound use in ED once again ${ }^{1-5}$.

KEYWORDS: pulmonary embolism, heart echocardiography, cardiogenic shock.

\section{Received: $20^{\text {th }}$ Mar 2013}

*Address for correspondence: Clinical Hospital Center Osijek, J. Huttlera 4, HR-31000 Osijek, Croatia.

Phone: +385-31-511-511

E-mail: andrea.dzumhur@gmail.com

\section{Literature}

1. Grifoni S, Olivotto I, Cecchini P, et al. Short-term clinical outcome of patients with acute pulmonary embolism, normal blood pressure, and echocardiographic right ventricular dysfunction. Circulation. 2000;101(24):2817-22.

2. Kreit JW. The impact of right ventricular dysfunction on the prognosis and therapy of normotensive patients with pulmonary embolism. Chest. 2004;125(4):1539-45.

3. ten Wolde M, Sohne M, Quak E, Mac Gillavry MR, Buller HR. Prognostic value of echocardiographically assessed right ventricular dysfunction in patients with pulmonary embolism. Arch Intern Med. 2004;164(15):1685-9.

4. Quiroz R, Kucher N, Schoepf UJ, et al. Right ventricular enlargement on chest computed tomography: prognostic role in acute pulmonary embolism. Circulation. 2004;109(20):2401-4.

5. Torbicki A, Perrier A, Konstantinides S, et al. Guidelines on the diagnosis and management of acute pulmonary embolism: the Task Force for the Diagnosis and Management of Acute Pulmonary Embolism of the European Society of Cardiology (ESC). Eur Heart J. 2008;29(18):2276-315. 